\title{
LA INTERPRETACIÓN JURÍDICA Y LA MATERIA FISCAL
}

Rogelio Larios Velasco

Lucila Caballero Gutiérrez ${ }^{1}$

SUMARIO: I. Nota introductoria. II. Sobre interpretación y sus directivas. III. Regulación jurídica fiscal de la interpretación. IV. Aplicación del derecho y sus clases. V. Vínculo entre aplicación e interpretación. VI. Oportunidad de la interpretación. VII. Jurisprudencia sobre la interpretación fiscal. VIII. Análisis y constitucionalidad del art. $5^{\circ}$ del Código Fiscal de la Federación. IX. Conclusiones. X. Bibliografía.

\section{RESUMEN}

En el marco de definiciones, clasificaciones y problemática de la interpretación jurídica y de sus reglas, y de argumentos en contra del apotegma clara non sunt interpretada, en el presente trabajo se realiza un análisis del precepto jurídico central en la regulación de la actividad hermenéutica dentro de la materia tributaria federal: el artículo 5으 del Código Fiscal de la Federación. También se analizan las tesis jurisprudenciales aplicables, y se lleva a cabo la valoración de la constitucionalidad de tal precepto. Esto se desarrolla a través de una metódica investigación conceptual de expresiones relevantes del lenguaje legal, jurisprudencial y constitucional, continentes de las nociones de "aplicación jurídica", "aplicación estricta", "aplicación no estricta", "interpretacióncomprensión”, "interpretación-explicación”, etc.

PALABRAS CLAVE: interpretación, hermenéutica, aplicación estricta, oscuridad legislativa, materia fiscal.

\footnotetext{
${ }^{1}$ Docentes Investigadores de Tiempo Completo, del Departamento de Derecho de la Universidad de Sonora, e-mail: lucila.caballero@unison.mx; rogelio.larios@unison.mx
} 


\title{
La interpretación jurídica y la materia fiscal
}

Año 11, Número 20, julio-diciembre de 2019

Rogelio Larios Velasco y Lucila Caballero Gutiérrez

\section{LEGAL INTERPRETATION AND TAX MATTER}

\begin{abstract}
Within the framework of definitions, classifications and problematic of the legal interpretation and its rules, and arguments against the apothegma clara non sunt interpreted, in this work, an analysis of the central legal precept in the regulation of the hermeneutical activity is carried out within Federal tax matters: Article 5 of the Federal Fiscal Code. The applicable jurisprudential theses are also analyzed, and the constitutionality of such precept is valued.This is developed through a methodical conceptual investigation of relevant expressions of legal, jurisprudential and constitutional language, continents of the notions of "legal application", "strict application", "non-strict application", "interpretation-understanding", "interpretation explaining ", etc.
\end{abstract}

KEYWORDS: interpretation, hermeneutics, strict application, darkness Legislative, tax matters.

\section{NOTA INTRODUCTORIA}

En virtud de que el tema de la interpretación jurídica en materia fiscal (y administrativa) fue tratado brillantemente por el ilustre jurista Emilio Margáin Manatou, en este artículo realizaremos algunos análisis adicionales sobre el mismo, como parte de su merecido homenaje. Al respecto, los autores ubicaremos, como antecedente y marco necesario de las reflexiones sobre el citado tema, algunas peculiaridades y clasificaciones tanto de la actividad hermenéutica como de las reglas que la justifican y orientan. Posteriormente, desarrollaremos algunos apartados que consideramos sirven de apoyo a las reflexiones apuntadas. Tales desarrollos tratan del concepto de "aplicación jurídica", el de su vínculo con la interpretación y el de las especies fundamentales de esta última. Como veremos, una de ellas es prácticamente consustancial con la aplicación del derecho. Respecto 
de la otra, se presentan argumentos contra la postura tradicional de cuándo debe interpretarse. Se harán comentarios en relación a algunas tesis jurisprudenciales, que no pueden soslayarse. Finalmente, aplicaremos todo lo anterior en la valoración de contenido y constitucionalidad del precepto regulatorio de la interpretación fiscal federal.

\section{SOBRE INTERPRETACIÓN Y DIRECTIVAS DE INTERPRETACIÓN}

Al margen de si la interpretación de normas de derecho es total o mayoritariamente atribuir o descubrir su sentido, nuestro sistema jurídico trata el término "interpretación" en dos formas principales: a) como comprensión de la norma aplicada, y b) como expresa explicación de la norma aplicada. Como se aprecia, en las dos formas hay determinado vínculo con el concepto "aplicación normativa". Este vínculo se tratará con cierto detalle adelante.

Es incorrecto afirmar que la norma jurídica que se interpreta y aplica tenga un significado único, evidente y descubierto mediante la observación; por el contrario siempre pueden surgir algunos de los siguientes problemas: conexiones de la norma aplicable con otras normas del mismo sistema, la intención del legislador, la circunstancia social en que la norma se aplica, la capacidad de comprensión por parte de los diversos receptores de la ley, vaguedad semántica tanto potencial como específica, polisemia, emotividad de las palabras o problemas de operatividad. Todo esto conduce a la diversidad de sentidos y al problema de elegir alguno. Como indica Roberto Vernengo: “... frente a una norma cualquiera son siempre posibles, por razones derivadas de las características lógicas de la relación, múltiples interpretaciones literales de la misma, según se presenten los intereses del intérprete y sus recursos expresivos."2

Las reglas de interpretación, también llamadas "elementos", "sistemas", "métodos", "técnicas", "cánones", etc., las denominaremos en este trabajo, en

2 Vernengo, Roberto. "Interpretación del derecho". El derecho y la justicia. Enciclopedia Iberoamericana de Filosofía. No. 11. Madrid: Trotta. 1996. P. 245. 


\section{La interpretación jurídica y la materia fiscal}

Año 11, Número 20, julio-diciembre de 2019

Rogelio Larios Velasco y Lucila Caballero Gutiérrez

principio, como "directivas". De acuerdo con Wróblewski, "las directivas interpretativas se utilizan para indagar sobre un significado o para justificar una decisión interpretativa. En cualquier caso, el significado de una regla legal interpretada depende de estas directivas." 3 Es decir, tales directivas tienen dos funciones básicas: a) orientar sobre cómo realizar una interpretación y b) la de justificar racionalmente una interpretación realizada.

Una manera usual de clasificar la interpretación de acuerdo al sujeto que la realiza parece no referirse a los intérpretes sino a la misma interpretación. Se trata de la denominada "interpretación auténtica" en oposición a la "no auténtica". La primera se refiere al considerado —en el Siglo XIX - único creador del derecho: el legislador. Esta clasificación, si seguimos a Guastini, ${ }^{4}$ se complementa con la oficial, judicial y doctrinal. Una similar presenta Hallivis: auténtica, judicial, doctrinal, administrativa, con los agregados de las interpretaciones popular o directa, de las partes y consensuada. ${ }^{5}$ En la literalidad de "interpretación oficial" se implica que los intérpretes son los funcionarios estatales, de "interpretación judicial", los jueces; de "interpretación doctrinal", los doctrinarios o juristas; de "interpretación administrativa", las autoridades administrativas; de "interpretación popular", el pueblo; de "interpretación de las partes", las partes en un proceso; de la "consensuada", por acuerdo de voluntades.

Una clasificación propiamente dicha de la interpretación es la que la divide en declarativa y correctora. La primera es la que sujetó la determinación de significado del texto legal al alcance semántico de las palabras del mismo y la

3 Wróblewski, Jerzy. Constitución y teoría general de la interpretación jurídica. Madrid: Cívitas.1998. P. 52.

4 Guastini, Riccardo. Estudios sobre la interpretación jurídica. México: PorrúaUNAM. 2001. P. 19.

${ }^{5}$ Hallivis Pelayo, Manuel. Teoría general de la interpretación. México: Porrúa. 2007. P. 291. 
correctora es la que modificó tal alcance. Según Guastini, la correctora comprende la restrictiva y la extensiva. ${ }^{6}$

Cuando se clasifica a la interpretación en histórica, sistemática, evolutiva, etc., tal clasificación es, en realidad, de directivas de interpretación y no de la interpretación en sí misma, porque los criterios clasificatorios son, en realidad, de las diversas directivas aplicadas: considerar los antecedentes jurídicos previos a la elaboración de la norma jurídica que se interpreta, considerar sus relaciones con otras normas del mismo sistema, considerar las actuales condiciones sociales de la norma que quiere interpretarse, etc. Con esto se confunde denominaciones de interpretación realizada con directivas que se aplicaron para realizarla; sin embargo, como la costumbre es fuerte para denominar a una interpretación de acuerdo al tipo de directiva que la apoya, nosotros la seguiremos, siendo conscientes de tal circunstancia.

Una clasificación necesaria para el propósito de este trabajo es la que distingue entre interpretaciones (más bien, entre directivas) textuales, contextuales y situacionales. Las primeras son las que se limitan específicamente a los aspectos semánticos y sintácticos del lenguaje utilizado en la norma interpretada. Ejemplos de éstas son la gramatical, de sentido general, a contrario sensu expreso, la apagógica, etc.

La segunda se vincula con la noción del Derecho como un sistema, por ello también se denomina "interpretación sistemática". Para Bunge, un contexto es un sistema propiamente dicho sólo si las proposiciones que lo componen tienen al menos un referente común. ${ }^{7}$ Tal referente común en el sistema jurídico mexicano es, obviamente, la Constitución Política de los Estados Unidos Mexicanos; así, una interpretación contextual es la que toma en consideración, para determinar el

${ }^{6}$ Otros autores se refieren también a la progresiva como diferente de la restrictiva y extensiva. Véase Cortés Ibarra, Miguel Ángel. Derecho penal. $3^{\mathrm{a}}$ ed. México: Cárdenas Editor. 1987. Pp. 65 y 66, en donde el autor sigue una línea de Luís Jiménez de Asúa.

${ }^{7}$ Bunge, Mario. Diccionario de filosofía. 4를 ed. México: Siglo XXI, 2007. P. 36. 


\section{La interpretación jurídica y la materia fiscal}

Año 11, Número 20, julio-diciembre de 2019

Rogelio Larios Velasco y Lucila Caballero Gutiérrez

sentido de la norma interpretada, a los aspectos semánticos y sintácticos del lenguaje utilizado en otras normas dentro del mismo sistema. En este sentido, cabe recordar que el contexto jurídico, en realidad, sólo se integra de los textos de otras normas. Ejemplos de interpretaciones contextuales: a coherentia, integración normativa, pro subjecta materia, constancia terminológica, contextualidad terminológica, lex specialis, topológica, etc.

Respecto a directivas situacionales, éstas se vinculan con la idea de que todo lenguaje y, por tanto, el lenguaje jurídico, requiere de una dimensión pragmática ${ }^{8}$ para poder cumplir su función comunicativa, además de la semántica y de la sintaxis. Al respecto, Alf Ross parte de la idea de que por sí misma "la interpretación no tiene un punto de partida lingüístico independiente, sino que desde el comienzo está determinada por consideraciones pragmáticas en la forma de sentido común". ${ }^{9}$ Esta pragmática se traduce en la necesidad de determinar la situación en que se utiliza tal lenguaje; respecto de la ley, situación es aquella circunstancia social en que fue emitido tanto el texto como el contexto de las normas interpretadas, así como la circunstancia social en que buscan aplicarse. De tales circunstancias pueden derivarse ciertas necesidades y valores: a) técnicos vigentes en la comunidad de los operadores del derecho, los cuales giran en torno a que el derecho pueda cumplir mejor su función regulativa social, y b) de justicia o morales vigentes en la comunidad en general o en la comunidad de los operadores del derecho. Ejemplos de interpretaciones situacionales: a pari ratione, a fortiori, de operatividad, disociación, evolutiva, histórica, de trabajos preparatorios, comparativa extranjera, etc.

\footnotetext{
${ }^{8}$ Marmor apunta que "una manera de considerar el objeto de la pragmática consiste en verlo como un intento de llenar este vacío entre el significado literal y aquello que realmente está siendo comunicado." Interpretación y teoría del derecho. Barcelona: Gedisa. 2001. P.41.

${ }^{9}$ Ross, Alf. Sobre el derecho y la justicia. Buenos Aires: EUDEBA. 1997. P. 182.
} 


\section{REGULACIÓN JURÍDICA FISCAL DE LA INTERPRETACIÓN}

La interpretación jurídica y sus directivas parten de una tradición antigua desde el Derecho romano clásico y enriquecida a través de los siglos. Tal tradición está basada principalmente, hasta nuestros días, en un carácter retórico o argumentativo. Pero a un lado de esta retórica, aparece un sustento jurídico en dos aspectos: $1^{\circ}$ el mismo derecho regula de manera expresa o implícita, la actividad de interpretación; es así que, prohíbe, permite u obliga el uso de ciertas directivas retóricas en ciertos ámbitos, o autoriza a ciertos órganos para realizarla; y $2^{\circ}$ el derecho crea nuevas directivas de interpretación que, por lo mismo, no pueden llamarse retóricas sino legales o, inclusive, constitucionales.

El precepto sustancial en materia de interpretación en materia fiscal federal es el artículo 5ำ del Código Fiscal de la Federación, el cual establece lo siguiente:

Las disposiciones fiscales que establezcan cargas a los particulares y las que señalen excepciones a las mismas, así como las que fijan las infracciones y sanciones, son de aplicación estricta. Se considera que establecen cargas a los particulares las normas que se refieren al sujeto, objeto, base, tasa o tarifa. Las otras disposiciones fiscales se interpretarán aplicando cualquier método de interpretación jurídica. A falta de norma fiscal expresa, se aplicarán supletoriamente las disposiciones del derecho federal común cuando su aplicación no sea contraria a la naturaleza propia del derecho fiscal. ${ }^{10}$

En principio podemos apuntar que el precepto citado se ubica en el primer aspecto de la regulación jurídica sobre la labor interpretativa: permite explícitamente cualquier método de interpretación para las normas fiscales que no establezcan cargas o sus excepciones y también, como se verá a continuación, permite y prohíbe implícitamente determinadas interpretaciones.

El art. $5^{\circ}$ en su primera parte alude a la aplicación de ciertas normas fiscales y no a su interpretación, pero como en la segunda parte señala "en los otros casos se puede aplicar cualquier método de interpretación jurídica" se infiere que la aplicación de normas que establecen cargas y sus excepciones (e infracciones y

${ }^{10}$ El artículo 11 del Código Fiscal de Sonora tiene un contenido muy similar. 


\section{La interpretación jurídica y la materia fiscal}

Año 11, Número 20, julio-diciembre de 2019

Rogelio Larios Velasco y Lucila Caballero Gutiérrez

sanciones), comprende también a la interpretación de tales normas. Así, como se trata de aplicación estricta entonces la exégesis también es estricta. Por tanto, tales normas se deben interpretar estrictamente, es decir, sujetándose a ciertas directivas de interpretación y evitando otras.

Permitir todo tipo de métodos de interpretación, respecto a otros casos, implica necesariamente aplicar normas fiscales, porque interpretación sin aplicación carece de sentido en la dinámica del derecho; no obstante, en tal supuesto (o sea, de normas que no establecen cargas, sus excepciones, infracciones y sanciones) tampoco es necesaria la interpretación explícita, siempre que se haga una aplicación que, en este caso, puede ser tanto estricta como no estricta.

Toda aplicación jurídica implica una interpretación entendida como comprensión de las normas aplicadas. ${ }^{11}$ Ésta es una hipótesis operativa sustentada en la idea de que el órgano aplicador necesariamente tuvo que entender lo que está aplicando. Como señala Mendonca: "para aplicar una norma, lo primero que se hace es tomar conocimiento de ella."12 En Kelsen aparece muy estrecho el vínculo entre aplicación e interpretación porque entiende por esta última, fundamentalmente, a la subjetiva y necesaria comprensión del significado de la norma para poder ser aplicada: "la interpretación es un procedimiento espiritual que acompaña el proceso de aplicación del derecho, en su tránsito de una grada superior a una inferior."13

La aplicación del derecho puede estar acompañada o no de una explícita interpretación, entendida como explicación de la normatividad correspondiente.

Para evaluar si tal aplicación es jurídicamente correcta o no, también se evalúa la implícita interpretación-comprensión confrontándola con una interpretación-explicación.

11 Al respecto, Wróblewski señala que “'Interpretación' en sentido amplio es sinónimo de 'comprensión' de una expresión cualquiera formulada en una lengua. Todo signo lingüístico para ser comprendido tiene que ser interpretado." Sentido y hecho en el derecho. Doctrina jurídica contemporánea. No. 9. México: Fontamara. 2001. P. 152.

12 Mendonca, Daniel. Las claves del derecho. Barcelona: Gedisa. 2008. P. 192.

${ }^{13}$ Kelsen, Hans. Teoría pura del derecho. México: Porrúa. 1997. P. 349. 
Al margen de lo anterior y respecto a la expresión "que establecen cargas a los particulares", ¿por qué "particulares" y no "contribuyentes"?, ¿qué no también las autoridades son contribuyentes? $\mathrm{O}$ acaso, ¿las que establecen cargas fiscales a las autoridades no se establecen en las leyes fiscales mexicanas?

Como señalamos en la nota introductoria, para el análisis el precepto citado, desarrollaremos en apartados posteriores los siguientes conceptos: de aplicación del derecho y sus diversas clases, relación entre aplicación e interpretación y oportunidades para realizar esta última. Sus conclusiones las relacionaremos con el artículo 5 del Código Fiscal apuntado.

\section{LA APLICACIÓN DEL DERECHO Y SUS CLASES}

Hans Kelsen señala que "aplicación del derecho es de consuno producción del derecho"14, es decir, en general, son equivalentes aplicar y producir derecho, pero con las excepciones en los extremos tanto de mayor como de menor jerarquía en la pirámide jurídica nacional: en la mayor, si se trata de la instauración de la primera Constitución histórica hay producción de derecho pero no aplicación. Respecto a la labor del Órgano Revisor de la Constitución en nuestro país, claramente al crear nuevo derecho constitucional también está aplicando derecho, al menos aplica el artículo 135 de la Carta Magna. Y en la menor jerarquía hay aplicación pero no producción jurídica cuando se trata de meros actos de ejecución de la norma. ${ }^{15}$

En contra de lo anterior, entre otros autores, Rafael de Pina señala que "la función aplicadora del derecho no permite ser confundida 'ni adicionada' con la creadora. Aparte de que ello es opuesto a la seguridad jurídica, desde el punto de vista de la legislación mexicana la creación judicial del derecho tiene el obstáculo

\footnotetext{
${ }^{14}$ Kelsen, Hans. Teoría pura del derecho, México, Porrúa. 1997. P. 244.

${ }^{15}$ Kelsen, Hans. Teoría pura del derecho, México, Porrúa. 1997. P. 246.
} 


\section{La interpretación jurídica y la materia fiscal}

Año 11, Número 20, julio-diciembre de 2019

Rogelio Larios Velasco y Lucila Caballero Gutiérrez

insuperable que le opone el principio de la división de los Poderes del Estado... ${ }^{16}$

La réplica de tal autor sólo se entiende desde el punto de vista decimonónico de que únicamente es derecho lo que produce el legislador y que todo lo demás es mera aplicación. Además, olvida que el legislador también cumple una función aplicadora: aplica la Constitución.

Si consideramos que "aplicación jurídica" es realizar alguna conducta (tanto productora como no productora de normas de todos los niveles) con sustento o apoyo en una norma de derecho y "producción jurídica" es crear, dentro de un sistema de derecho, una norma (tanto general como particular) que no existía, entonces Kelsen está, en general, acertado.

Podemos sintetizar, que mayoritariamente quien aplica el derecho es el órgano jurídico, es decir, quien produce más derecho, o sea, creación de nuevos derechos y obligaciones. Pero si aplicar es usar, también aplica el derecho quien sólo lo acata, trátese de particulares o de autoridades (estas últimas, como indicó Kelsen, cuando ejecutan resoluciones).

Podemos entender que existe aplicación estricta cuando se utiliza una norma o normas a un caso concreto y la descripción de éste se ajusta o corresponde al texto $o$ al contexto de tales normas. Similar ocurre en materia penal, de acuerdo a la prescripción "queda prohibido imponer... pena alguna que no esté decretada por una ley exactamente aplicable al delito de que se trata", del 3er párrafo del 14 constitucional, y quizá en grado mayor si entendemos que lo "exactamente aplicable" es todavía más exigente que la "aplicación estricta". En relación a las diversas clases de interpretación (y de sus directivas) podemos entender que la aplicación estricta permite todas las textuales y contextuales, e impide las diversas interpretaciones situacionales.

Por su parte, entendemos que existe aplicación no estricta cuando se aplican normas jurídicas a un caso concreto aun cuando la descripción de este último no se ajuste o corresponda al texto ni al contexto de las normas aplicadas. Podemos

${ }^{16}$ De Pina, Rafael y De Pina Vara, Rafael. Diccionario de derecho: México: Porrúa. 1996. P. 94 
entender que la aplicación no estricta permite toda clase de interpretación textual, contextual y situacional.

Como ejemplos de algunas de las especies de la aplicación no estricta tenemos a la aplicación analógica y a la aplicación por mayoría de razón. Estas son conocidas porque se encuentran expresamente prohibidas por el 14 constitucional al aplicar sanciones penales. Construir un concepto aproximado de tales especies de aplicación no estricta, requiere necesariamente la consideración del concepto de las directivas de interpretación correspondientes, aunque al realizarse tales aplicaciones de normas de derecho, no esté presente alguna interpretación explícita, es decir, puede sólo llevarse al cabo la aplicación. Sin embargo, como señalamos antes, una aplicación así presupone, por parte del órgano aplicador, una interpretación como comprensión del significado de la norma.

Respecto de la aplicación analógica, tenemos que la directiva de interpretación analógica, a pari ratione o a similli ratione consiste en que "si existen similitudes relevantes entre el supuesto previsto en la norma y otra situación no prevista, entonces debe atribuirse un significado a la norma, de forma que se extiendan las consecuencias normativas a la situación no prevista." ${ }^{17}$ Se utiliza el principio ubi eadem legis ratio ibi eadem legis dipositio (donde hay la misma razón, rige la misma disposición). Considerando lo anterior, tenemos que la aplicación analógica del derecho, sin necesidad de interpretación explícita alguna, ocurre cuando el caso concreto no corresponde con la literalidad del supuesto de la norma cuyas consecuencias jurídicas se le imponen, pero que tiene similitudes relevantes con tal supuesto.

Respecto de la aplicación por mayoría de razón, tenemos la directiva de interpretación a fortiori en su especie a maiori ad minus cuyo concepto es el siguiente: "si dentro del mismo género conductual del permiso o derecho otorgado explícitamente por la norma legal existe una conducta de menor importancia, entonces se debe otorgar un significado a esa norma extendiendo el permiso o

${ }^{17}$ Larios, Rogelio y Caballero, Lucila. Las directivas de Interpretación jurídica. Hermosillo: Unison-Fontamara. 2011. P. 146. 


\section{La interpretación jurídica y la materia fiscal}

Año 11, Número 20, julio-diciembre de 2019

Rogelio Larios Velasco y Lucila Caballero Gutiérrez

derecho a esa conducta." ${ }^{18}$ Aquí se aplica el principio "quién tiene permiso de hacer lo más tiene permiso de hacer lo menos". Considerando lo anterior, tenemos que la aplicación del derecho por mayoría de razón en su primera especie, sin necesidad de interpretación explícita alguna, ocurre cuando el caso concreto no corresponde con la literalidad del supuesto de la norma cuyas consecuencias jurídicas se le imponen, pero consiste en una conducta de menor importancia que la permitida y forma parte del género de la misma. También tenemos la directiva de interpretación a fortiori en su especie a minori ad maius cuyo concepto es el siguiente: "si dentro del mismo género conductual de la prohibición que establece la norma legal existe una conducta de mayor importancia, entonces se debe atribuir un significado a esa norma extendiendo la prohibición derecho a esa conducta." ${ }^{19}$ Aquí se usa el principio "quién tiene prohibido hacer lo menos tiene prohibido hacer lo más". Considerando lo anterior, tenemos que la aplicación del derecho por mayoría de razón en su segunda especie, sin necesidad de interpretación expresa alguna, ocurre cuando el caso concreto no corresponde con la literalidad del supuesto de la norma cuyas consecuencias jurídicas se le imponen, pero tal caso consiste en una conducta de mayor importancia que la prohibida y forma parte del género de la misma.

\section{VÍNCULO ENTRE APLICACIÓN E INTERPRETACIÓN}

Existen dos aspectos que deseamos comentar sobre vínculo entre el concepto de "aplicación del derecho" y el de "interpretación" explícita. El primero, antiguo - y esperemos ya superado-, consiste en ubicarlos como opuestos entre sí. De esta manera, tradicionalmente se ha considerado que "aplicación del derecho" es equivalente a "aplicación de la letra de la ley" y que la "interpretación" modifica el contenido de la ley a diferencia de la aplicación de su letra que se traduce en respeto a tal contenido.

${ }^{18}$ Larios, Rogelio y Caballero, Lucila. Las directivas de Interpretación jurídica. Hermosillo: Unison-Fontamara. 2011. P. 141.

${ }^{19}$ Larios, Rogelio y Caballero, Lucila. Las directivas de Interpretación jurídica. Hermosillo: Unison-Fontamara. P. 142. 
Pensar que la interpretación es modificación de la ley es un error porque puede existir interpretación sin modificar la ley, así como puede existir una modificación inválida de la ley (por ejemplo, la de un juez) sin haber interpretación explícita. También pensar que la aplicación de la letra de la ley necesariamente implica no interpretar, es inexacto porque tal aplicación supone siempre una interpretación-comprensión y puede ser realizada junto con una expresa interpretación literal (la aplicación de la ley puede realizarse sin y con interpretación explícita, así como puede existir interpretación sin aplicación, aunque esto último sólo tiene interés académico). Como indicó Karl Larenz: "ya la constatación de que el sentido literal resulta evidente este o aquel significado es, por regla general, el resultado de una interpretación." 20 Actualmente, se acepta la idea de que la interpretación literal o gramatical no es una mera descripción de la norma correspondiente, sino una reformulación lingüística sujeta a las palabras textuales. ${ }^{21}$

El segundo aspecto consiste en el cuestionamiento sobre si la interpretación expresa es necesaria para una correcta aplicación del derecho o, específicamente, para fundamentar sólidamente una resolución judicial o administrativa. Al respecto, en general, para poder realizar la aplicación del derecho no es necesaria tal explicitación, esto se aprecia en los siguientes ejemplos reiterados: el legislador aplica la Constitución al expedir una ley, sin interpretar la Ley Suprema en la exposición de motivos; la autoridad administrativa al aplicar la ley lo hace "con fundamento en los artículos $x, y, z$ y demás aplicables", sin expresar interpretación alguna, etcétera.

Además, si consideramos que toda norma jurídica tiene más de un significado, ¿es posible fundamentar sólidamente una resolución judicial o administrativa sin expresar una interpretación? Consideramos que, a pesar de la

20 Larenz, Karl. Metodología de la ciencia del derecho. Barcelona: Ariel. 1994. P. 341.

21 “[...] la interpretación siempre expresará algo más que el texto y por ello una lectura literal no es interpretación sino sólo una descripción." Pérez Carrillo, Agustín, "Hermenéutica e interpretación jurídica". La derrotabilidad del derecho. Biblioteca de Filosofía del Derecho y Política. No. 89. México: Fontamara. 2003. P. 70. 


\section{La interpretación jurídica y la materia fiscal}

Año 11, Número 20, julio-diciembre de 2019

Rogelio Larios Velasco y Lucila Caballero Gutiérrez

perpetua diversidad de sentidos de toda normatividad y de que sería deseable que, al menos en la mayoría de los casos se hiciera tal expresión, sí es posible tal acción si se cumplen los siguientes requisitos dentro del silogismo jurídico que sustenta tales resoluciones: $1^{\circ}$ que dentro del procedimiento correspondiente no exista controversia sobre el significado de la norma aplicable; $2^{\circ}$ que la descripción del contenido normativo del supuesto de la norma aplicable sea verdadera, es decir, que corresponda con el texto de la norma descrita; 3ํque la descripción del texto normativo claramente corresponda a la descripción del hecho dentro de la premisa del caso, y que motiva la resolución; 4ํque la descripción del hecho sea verdadera, o sea, que se encuentre tal hecho probado.

Finalmente podemos indicar que si la ley prescribe cierta aplicación, esto constriñe a la actividad interpretativa como comprensión que va implícita en la actividad aplicadora, ${ }^{22}$ y también sujeta a la interpretación explícita, en caso de que ocurra. Por otro lado, si la ley obliga cierta interpretación, esto sujeta a cómo aplicar la norma y a su implícita interpretación de cómo se entendió la norma aplicada, sin embargo, ello no significa que siempre se debe realizar explícitamente una interpretación, sólo que si ocurre deber ser de la clase prescrita. Por ejemplo, el segundo párrafo del artículo $1^{\circ}$ constitucional prescribe: "Las normas relativas a los derechos humanos se interpretarán de conformidad con esta Constitución y con los tratados internacionales de la materia favoreciendo en todo tiempo a las personas la protección más amplia." El verbo en futuro "interpretarán" denota claramente la obligatoriedad de interpretar. ¿Esto significa que en tal supuesto si alguna autoridad no realiza una interpretación explícita significa, ipso facto, que está incumpliendo con el mandato constitucional? Consideramos que por el uso sistemático que hace

22 Al respecto, Schmill y Cossío indican: “... en el momento en que el legislador, por ejemplo, pretenda crear una ley para regular una materia respecto de la cual la Constitución le confiera competencia, ha de comenzar por darle un sentido concreto a la norma constitucional que prevé tal competencia. Igualmente cuando los particulares pretenden celebrar un contrato entre sí, ambos habrán de darle una significación a la norma general en la cual se precisan, por ejemplo, la materia, los requisitos o los efectos del propio contrato." "Interpretación del derecho y concepciones del mundo". Interpretación jurídica y decisión judicial. Doctrina jurídica contemporánea. No. 4. 2ª ed. México: Fontamara. 2001. P. 60. 
la Constitución y la legislación mexicana sobre las palabras "aplicación" e interpretación", la respuesta es negativa. Sin embargo, la autoridad está obligada a realizar una aplicación que sea conforme con la Constitución y los tratados internacionales, y su implícita interpretación como comprensión de significado debe tener las características que exige la Constitución. En cambio, si la tal autoridad hace una interpretación explícita en tal caso, obviamente también debe tener tales características.

Aunque no es jurídicamente necesario que ocurra, sería deseable que explícitamente se interpretara la norma para justificar mejor la fundamentación correspondiente. En un contemporáneo Estado de derecho democrático, caracterizado por una mayoritaria eficacia en el respeto a los derechos humanos, la interpretación explícita permite que los particulares puedan conocer más fácilmente las razones por las que se les aplica tal o cual norma en cierto sentido y no en otro. Es más fácil para el gobernado defenderse contra una interpretación explícita que contra una subjetiva comprensión implícita. Así, se logra mayor confianza social en la autoridad.

\section{OPORTUNIDAD DE LA INTERPRETACIÓN}

Un aspecto relevante de la interpretación jurídica es la cuestión ¿cuándo debe interpretarse la norma que se busca aplicar? La respuesta tradicional es cuando exista incertidumbre u oscuridad de la ley: clara non sunt interpretada, in claris non fit interpretatio o interpretatio cessat in claris. La misma respuesta se apreciará en una de las tesis jurisprudenciales que se comentan adelante. Esto obviamente se refiere a la interpretación-explicación y no a la implícita interpretación-comprensión.

El problema con la incertidumbre u oscuridad de la ley $y$, por tanto, con el apotegma citado, es que se encuentran en el ámbito de lo subjetivo: en principio, la claridad u oscuridad de la ley puede variar dependiendo de los intereses de las partes. Mendonca señala que: "toda interpretación es, así, en definitiva, una propuesta de lectura y, por plausible que parezca, casi siempre enfrenta alguna 


\section{La interpretación jurídica y la materia fiscal}

Año 11, Número 20, julio-diciembre de 2019

Rogelio Larios Velasco y Lucila Caballero Gutiérrez

alternativa..."23 Tal subjetivismo puede intentar reducirse si estos conceptos se vinculan con los clásicos problemas lingüísticos del derecho: ambigüedad, vaguedad o incertidumbre semántica - tanto grave como de textura abierta-, anfibología y el absurdo textual. Sin embargo, tal reducción de subjetivismo tiene las siguientes dificultades: $1^{\underline{a}}$ a excepción de los nombres propios, todas o casi todas las palabras son ambiguas y todas tienen, al menos, el problema de la vaguedad de textura abierta, esto significa que prácticamente siempre habría incertidumbre (o sea, casi nunca hay "claridad") y, por tanto, la necesidad de interpretar; $2^{\mathrm{a}}$ aunque existan tales problemas, realmente hay situaciones en que puede no ser necesaria la interpretación; $3^{a}$ tales problemas lingüísiticos no son los únicos que determinan cuándo tiene que realizarse una interpretación.

El problema anterior puede replantearse de otra manera: independientemente de si se trata de una interpretación basada en directivas legales o en directivas retóricas reguladas expresa o implícitamente por el derecho, para una mejor racionalidad en la actividad operativa del derecho ¿cuál es el momento oportuno para interpretar?

Debido al subjetivismo anterior, dentro de un procedimiento jurídico, en general, cualquier participante puede interpretar a su libre voluntad en sus documentos procesales, pero existen situaciones en que es razonablemente conveniente realizar una interpretación de la ley al aplicarse ésta, desde el punto de vista de una de las partes en un proceso respecto del argumento de la otra parte o del juzgador, o bien desde el punto de vista del juzgador respecto de los argumentos de alguna de las partes.

A continuación, describiremos algunas de tales situaciones.

1a Hacer una interpretación textual (e inclusive contextual) aclaratoria, precisamente, en la situación menos subjetiva a la que pueden relacionarse las expresiones "incertidumbre sobre lo literal" u "oscuridad de la ley", esto es,

\footnotetext{
${ }^{23}$ Mendonca, Daniel. Las claves del derecho. Barcelona: Gedisa. 2008. P. 192.
} 
cuando la norma aplicable (no sólo en su texto, sino también en su contexto porque éste también puede ser "oscuro") presenta especiales problemas de ambigüedad, vaguedad, anfibología o absurdo textual.

$2^{\text {a }}$ Hacer una interpretación contextual cuando se justifica jurídicamente la desviación del texto de la norma primariamente aplicable porque debe prevalecer la aplicación del contexto.

3 ${ }^{\text {a }}$ Hacer una interpretación situacional cuando se justifica jurídicamente la desviación del texto de la norma en principio aplicable, porque debe prevalecer uno de sus significados situacionales.

4- Hacer una interpretación textual cuando, en contra de nuestros intereses, la autoridad (o la contraparte) aplica la norma en la que se fundamenta a un caso, desviándose de su texto (o existe el riesgo de que se desvíe) sin justificar tal desviación con una interpretación situacional o contextual.

5a Hacer una interpretación contextual o sistemática cuando, en contra de nuestros intereses, la autoridad (o la contraparte) aplica la norma (con o sin interpretación textual) en que se fundamenta a un caso que corresponde a su texto, pero lo jurídicamente correcto es que se desvié porque debe prevalecer una aplicación del contexto legal.

6 ${ }^{\underline{a}}$ Hacer una interpretación situacional o pragmática cuando, en contra de nuestros intereses, la autoridad (o la contraparte) aplica la norma (con o sin interpretación textual) en que se fundamenta a un caso que corresponde a su texto, pero lo jurídicamente correcto es que se desvié porque debe prevalecer una aplicación situacional.

Como se aprecia, exceptuando la primera situación, todas las demás pueden ocurrir sin que las normas aplicables presenten especiales problemas de ambigüedad, vaguedad, anfibología o absurdo textual, es decir, sin que haya "incertidumbre u oscuridad de la ley".

Finalmente podemos sintetizar que si se ubicó una sola norma la aplicable a un caso, se puede realizar una interpretación textual y, quizá, una situacional. Si se 


\section{La interpretación jurídica y la materia fiscal}

Año 11, Número 20, julio-diciembre de 2019

Rogelio Larios Velasco y Lucila Caballero Gutiérrez

ubicaron varias normas, entonces se puede realizar una interpretación sistemática y, quizá, una situacional.

\section{JURISPRUDENCIA SOBRE LA INTERPRETACIÓN FISCAL}

Tesis jurisprudenciales necesarias sobre el mismo tema son las indicadas a continuación:

CONTRIBUCIONES. LAS DISPOSICIONES REFERENTES A SUS ELEMENTOS ESENCIALES, AUNQUE SON DE APLICACIÓN ESTRICTA, ADMITEN DIVERSOS MÉTODOS DE INTERPRETACIÓN PARA DESENTRAÑAR SU SENTIDO. EI hecho de que el legislador haya establecido que las disposiciones fiscales que prevén elementos esenciales, como son sujeto, objeto, base, tasa o tarifa de una contribución y las excepciones a ésta, son de aplicación estricta, no significa que el intérprete no pueda acudir a los diversos métodos que permiten conocer la verdadera intención del creador de aquellas disposiciones, cuando de su análisis literal en virtud de las palabras utilizadas, sean técnicas o de uso común, se genere incertidumbre sobre su significado, ya que el efecto de lo ordenado por el legislador es obligar a aquél a que realice la aplicación estricta de la respectiva hipótesis jurídica única y exclusivamente a las situaciones de hecho que coincidan con lo previsto en ella, una vez desentrañado su alcance. ${ }^{24}$

INTERPRETACIÓN DE LAS NORMAS FISCALES QUE ESTABLECEN LOS ELEMENTOS ESENCIALES DE LOS TRIBUTOS. SU ALCANCE EN RELACIÓN CON LOS PRINCIPIOS CONSTITUCIONALES DE LEGALIDAD TRIBUTARIA Y SEGURIDAD JURÍDICA. Si bien es verdad que el juzgador, al momento de definir los elementos esenciales del tributo, debe partir del texto literal de la norma, como exigencia lógica de su aplicación al caso concreto, ello no implica que le esté prohibido acudir a los diversos métodos de interpretación reconocidos por la ciencia jurídica. Esto es así, ya que los principios de legalidad tributaria y de seguridad jurídica, y las disposiciones legales que establecen fórmulas dirigidas a condicionar

${ }^{24}$ Tesis 2a ./J. 133/2002, Seminario Judicial de la Federación y su Gaceta, Novena Época, Diciembre de 2002, Tomo XVI, p. 238. 
la aplicación y la interpretación de las normas tributarias, deben entenderse únicamente en el sentido de impedir aplicaciones analógicas en relación con los elementos esenciales de los tributos. ${ }^{25}$

Respecto de la jurisprudencia del 2002, podemos subrayar su señalamiento de que aunque las normas fiscales que establecen cargas "son de aplicación estricta, no significa que el intérprete no pueda acudir a los diversos métodos [de interpretación]". Tal aclaración podría deberse a que busca refutar dos posibles tesis sobre el significado de la exigencia de realizar una aplicación estricta: $1^{\stackrel{a}{a}}$ que ello excluye todo tipo de interpretación; $2^{\mathrm{a}}$ que sólo se puede realizar una interpretación estricta o literal, evitando cualquier otro tipo de interpretación. Aunque es cierto que las dos tesis son falsas, el señalamiento de la jurisprudencia es impreciso porque debió excluir a los métodos de interpretación situacional que son incompatibles con una aplicación estricta.

Otro señalamiento de la misma, a valorar, es que el uso de tales métodos de interpretación debe realizarse cuando del análisis literal de las normas se genere incertidumbre sobre su significado. Como vimos antes, esta condición para interpretar es subjetiva y reducida.

Un señalamiento adicional de la tesis es que la aplicación estricta se da única y exclusivamente cuando las situaciones de hecho coinciden con lo previsto en la respectiva hipótesis jurídica. Al respecto, sólo puntualizaríamos que tales situaciones coincidan con lo previsto no sólo en la hipótesis del texto, sino también en la del contexto jurídico. Como acertadamente indica Margáin Manatou: "Es un error el pensar que toda norma jurídica debe interpretarse en sus términos, en forma aislada de las demás disposiciones que constituyen la ley y no en forma armónica. Pretender esto es destruir todo el mecanismo que el legislador ha incorporado en una ley tributaria." 26

25 Tesis 2ª./J. 26/2006, Seminario Judicial de la Federación y su Gaceta, Novena Época, Marzo de 2006, Tomo XXIII, p. 270.

${ }^{26}$ Margáin Manatou, Emilio. Introducción al estudio del derecho tributario mexicano. $17^{a}$ ed. México: Porrúa. 2004. P. 149. 


\section{La interpretación jurídica y la materia fiscal}

Año 11, Número 20, julio-diciembre de 2019

Rogelio Larios Velasco y Lucila Caballero Gutiérrez

Respecto de la jurisprudencia de 2006, continúa la idea de que tratándose de los elementos esenciales del tributo el juzgador debe partir del texto literal de la norma para su aplicación al caso concreto. Reiteramos en puntualizar que también se debe partir del contexto literal de la norma.

De forma similar a la jurisprudencia anterior, alude a que la aplicación del texto literal de la norma no impide acudir a los diversos métodos de interpretación reconocidos por la ciencia jurídica, pero mejorando a la tesis previa con el agregado de que sí impide la aplicación analógica de los elementos esenciales de los tributos, en virtud de "los principios de legalidad tributaria y de seguridad jurídica" etc. Podemos comentar que tal agregado es correcto, pero insuficiente, porque existen adicionales formas de aplicación de la ley (y su correspondiente interpretación) que también son incompatibles con aplicar estrictamente la ley: por ejemplo, la ya comentada aplicación por mayoría de razón, la aplicación evolutiva, la conectada con los trabajos preparatorios del legislador, etc.

\section{ANÁLISIS Y CONSTITUCIONALIDAD DEL ARTÍCULO 5 DEL CÓDIGO FISCAL DE LA FEDERACIÓN}

Con base en el análisis de los apartados anteriores, podemos concluir para el artículo $5^{\circ}$ del Código Fiscal que la aplicación de normas que establezcan cargas o sus excepciones, al ser estricta, debe realizarse de tal forma que la descripción del caso concreto efectivamente corresponda con el texto o el contexto de tales normas. Esta aplicación estricta permite toda clase de interpretación textual y contextual, y sólo impide las diversas interpretaciones situacionales y, obviamente, la aplicación no estricta.

En relación a las normas fiscales que no establezcan cargas o sus excepciones (ni infracciones o sanciones), puede concluirse que al permitir el uso "de cualquier método de interpretación jurídica" se permite, por tanto, la aplicación no estricta, la cual significa que se pueden imputar consecuencias jurídicas a un caso concreto aunque la descripción de este último no se ajuste o no corresponda al texto ni al contexto de las normas aplicadas. Junto con esto, tal aplicación permite toda clase de interpretación textual, contextual y situacional. 
Dentro de la base en la Constitución de la República del Código Fiscal de la Federación y, por tanto, de su artículo $5^{\circ}$ se encuentra el art. 31: "Son obligaciones de los mexicanos: ...IV. Contribuir para los gastos públicos, así de la Federación, como de los Estados, de la Ciudad de México y del Municipio en que residan, de la manera proporcional y equitativa que dispongan las leyes." Art. 73, fracción VII: "Para imponer las contribuciones necesarias a cubrir el Presupuesto." XXIX: "Para establecer contribuciones:..." Art. 131 "Es facultad privativa de la Federación gravar..."Además, se considera que es aplicable a la materia fiscal (y a su artículo $\left.5^{\circ}\right)$ el último párrafo del 14 constitucional con apoyo en que la doctrina sostiene lo siguiente:

Dentro del rubro juicios del orden civil, se comprende todos aquellos procedimientos del orden común incluyendo juicios familiares, mercantiles y los propiamente civiles. A falta de otra disposición que lo garantice, el derecho a que una sentencia sea emitida en los términos del último párrafo del art. 14, también alcanza a los laudos y las resoluciones que se emiten en los procedimientos laborales y administrativos. ${ }^{27}$

Conviene aclarar que la expresión "en los juicios del orden civil" que emplea el último párrafo del artículo 14, se utiliza en contraposición a los "juicios del orden criminal" del párrafo tercero, por lo que la primera debe ser entendida en sentido amplio, de tal modo que no sólo incluya los juicios civiles que se regulan en los códigos de procedimientos civiles, sino también los mercantiles, los laborales y todos aquellos que no puedan ser ubicados dentro del tercer párrafo del artículo $14 .^{28}$

Y también existe una tesis aislada de la Suprema Corte que indica lo siguiente:

JUICIOS DEL ORDEN CIVIL. LA EXPRESIÓN RELATIVA, CONTENIDA EN EL ARTÍCULO 14, PÁRRAFO CUARTO, DE LA CONSTITUCIÓN GENERAL DE LA

${ }^{27}$ Arteaga Nava, Elisur. Garantías individuales. México: Oxford. 2009. P. 159.

${ }^{28}$ Ovalle Favela, José. Garantías constitucionales del proceso. México: McGrawHill. 1997. P. 83. 


\section{La interpretación jurídica y la materia fiscal}

Año 11, Número 20, julio-diciembre de 2019

Rogelio Larios Velasco y Lucila Caballero Gutiérrez

REPÚBLICA, SE APLICA TAMBIÉN A LOS JUICIOS EN MATERIA ADMINISTRATIVA (EN SENTIDO AMPLIO) Y LABORAL. El citado precepto, al establecer que en los juicios del orden civil, la sentencia definitiva deberá ser conforme a la letra o a la interpretación jurídica de la ley, y a falta de ésta se fundará en los principios generales del derecho, no debe interpretarse en el sentido de que sólo rige para los juicios civiles, esto es, el Constituyente introdujo esa referencia para distinguir a los juicios del orden penal del resto de los procedimientos de diversa materia, lo que significa que la expresión "en los juicios del orden civil" se aplica también a los juicios en materia administrativa (en sentido amplio) y laboral, así como a los propiamente civiles. ${ }^{29}$

Si de acuerdo con lo anterior, tal precepto constitucional es aplicable a la materia fiscal, entonces haremos alguna exégesis de sus principales expresiones. "Conforme a la letra de la ley" significa la aplicación estricta de la ley. Las razones son las siguientes: la "letra" es tanto el texto como el contexto de las normas aplicables -el contexto también es "letra" de la ley. Como vimos, tal aplicación implica, necesariamente, una interpretación-comprensión y la posibilidad de una explícita "interpretación-explicación", las dos sujetándose a lo textual y contextual. Por su parte, la expresión "conforme a su interpretación" significa que se permite la aplicación no estricta. La razón radica en que, como argumentamos antes, toda referencia jurídica a la "interpretación" implica necesariamente la aplicación de las normas interpretadas, de lo contrario, no tendría sentido tal interpretación. Además, el sentido de distinguir entre una aplicación conforme a la letra de la ley y una aplicación vía la referencia a la "interpretación", es diferenciar esta última de algo que no sea la letra de la ley, es decir, la posibilidad de desviarse de la letra: la aplicación no estricta. En este último caso, tanto la "interpretación-comprensión" implicada en tal aplicación como la posible "interpretación-explicación" pueden ser también situacionales, es decir, pueden apartarse del texto y contexto de las normas aplicadas.

29 Tesis 2a../A. XCVIII/2009, Seminario Judicial de la Federación y su Gaceta, Novena Época, Agosto de 2009, Tomo XXX, p. 226. 
Si lo anterior es correcto, entonces de acuerdo a la Constitución tratándose de materia no penal es competencia del juez decidir, de acuerdo a su mejor sentido de justicia en derecho, si realiza una aplicación estricta o no estricta. En relación a esto hay que observar que el precepto constitucional no distingue, en la citada materia, temas legales especiales que constriñan a los jueces a realizar determinada aplicación, como si se hace respecto de la materia penal en el párrafo anterior (cuando se trata de aplicar sanciones penales).

En el marco anterior, el artículo $5^{\circ}$ del Código Fiscal de la Federación al establecer la aplicación estricta sólo para las normas que establezcan cargas y sus excepciones, y la posibilidad de lo no estricto para las otras normas fiscales, es inconstitucional.

Por otro lado, es probable que el artículo $5^{\circ}$ sea innecesario por las razones que se exponen a continuación.

Es evidente que la autoridad fiscal en su aplicación de las leyes tributarias no puede, vía una aplicación-interpretación no estricta, establecer nuevas cargas fiscales o excepciones (ni nuevas infracciones o sanciones), porque eso es competencia del legislador. Existe la conocida excepción de los impuestos al comercio exterior, pero esta es una excepción que requiere facultad explícita del Congreso de la Unión de acuerdo al art. 131 constitucional.

Además, la aplicación estricta fiscal no neceariamente favorece al gobernado como sí lo hace la aplicación estricta en materia penal. En esta última, en caso de duda (derivada no sólo de la insuficiencia probatoria sino también de la incertidumbre semántica de la norma penal) no hay delito y no se aplica la sanción penal (in dubio pro reo); en cambio, en materia fiscal, en caso de duda (sobre cargas y sus excepciones, infracciones y sanciones) existe la controversia, apuntada por 


\section{La interpretación jurídica y la materia fiscal}

Año 11, Número 20, julio-diciembre de 2019

Rogelio Larios Velasco y Lucila Caballero Gutiérrez

Margaín Manatou, sobre cuál de las tesis debe prevalecer: la de indubio contra Fiscum o la de indubio Pro-Fiscum. ${ }^{30}$

\section{CONCLUSIONES}

1a Nuestro sistema jurídico trata el término "interpretación" como comprensión y como expresa explicación, de la normatividad aplicada.

2a La interpretación textual se limita a los aspectos semánticos y sintácticos del lenguaje de la norma. La contextual considera los mismos aspectos pero del lenguaje de otras normas del mismo sistema. La situacional se apoya en la circunstancia social en que fueron emitidos, o en que busca aplicarse, tanto el texto como el contexto, normativos, y se vincula con el valor del mejor cumplimiento del derecho en su función regulativa social, y el de justicia o moral vigente, en la comunidad.

$3^{\text {a }}$ Aplica el derecho tanto el órgano jurídico, es decir, quien produce nuevos derechos y obligaciones, como quien sólo lo acata, trátese de particulares o de autoridades.

4⿳亠 Toda aplicación jurídica implica una interpretación entendida como comprensión de las normas aplicadas. Ésta es una hipótesis operativa sustentada en la idea de que el órgano aplicador necesariamente tuvo que entender lo que está aplicando.

5a Existe aplicación estricta cuando se utiliza una norma o normas en relación a un caso concreto y la descripción de éste se ajusta o corresponde a su texto o contexto. Tal aplicación permite toda interpretación textual o contextual, e impide la situacional.

6 Existe aplicación no estricta cuando se usan normas jurídicas a un caso concreto aunque la descripción de este último no se ajuste ni corresponda a su texto ni a su contexto. Esta aplicación permite toda clase de interpretación textual, contextual y situacional.

\footnotetext{
${ }^{30}$ Margáin Manatou, Emilio. Introducción al estudio del derecho tributario mexicano. México: Porrúa. 2004. Pp. 146 y 147.
} 
$7^{\text {a }}$ La aplicación analógica del derecho, sin necesidad de interpretación explícita, ocurre cuando el caso concreto no corresponde con la literalidad del supuesto de la norma, pero tiene similitudes relevantes con el contenido del mismo.

8 ${ }^{\text {a }}$ La aplicación del derecho por mayoría de razón ocurre cuando el caso concreto no corresponde con la literalidad del supuesto de la norma pero, en su primera especie, consiste en una conducta de menor importancia que la permitida y forma parte del género de la misma. $Y$, en su segunda especie, tal caso consiste en una conducta de mayor importancia que la prohibida y forma parte del género de la misma.

9 Si la ley prescribe cierta aplicación, constriñe a la implícita interpretacióncomprensión y también, en caso de realizarse, a la interpretación-explicación. Si la ley obliga a cierta interpretación, sujeta a cómo aplicar la norma y a su implícita interpretación-comprensión, pero no significa que siempre debe explicitarse una interpretación.

10 a Aunque no es jurídicamente necesario, sería deseable que explícitamente se interpretara la normatividad aplicada para justificar mejor la fundamentación correspondiente en el marco de un auténtico Estado de derecho democrático.

$11^{\text {a }}$ Existen situaciones en que conviene realizar una interpretación de la ley al aplicarse ésta, y que van más allá de la "oscuridad de la ley" porque ésta es eminentemente subjetiva y muchas veces depende de los intereses de las partes.

$12^{\mathrm{a}}$ De acuerdo al artículo 14, cuarto párrafo, constitucional, es competencia del juez decidir si realiza una aplicación estricta o no estricta, sin distinguirle temas legales especiales que lo constriñan a realizar una $u$ otra. Si tal precepto comprende todo lo no penal, como es lo fiscal, entonces el artículo $5^{\circ}$ del Código Fiscal de la Federación, al establecer la aplicación estricta sólo para las normas que establezcan cargas y sus excepciones, y la posibilidad de lo no estricto para las otras normas fiscales, es inconstitucional.

$13^{\text {a }}$ Es probable que el artículo $5^{\circ}$ sea innecesario porque la autoridad fiscal no puede válidamente con una aplicación no estricta establecer nuevas cargas fiscales, sus excepciones, infracciones y sanciones, y porque la aplicación estricta 


\section{La interpretación jurídica y la materia fiscal}

Año 11, Número 20, julio-diciembre de 2019

Rogelio Larios Velasco y Lucila Caballero Gutiérrez

fiscal no necesariamente favorece al gobernado como sí lo hace la aplicación estricta en materia penal. 


\section{BIBLIOGRAFÍA}

ARTEAGA NAVA, Elisur, Garantías individuales. México,Oxford,2009

BUNGE, Mario, Diccionario de filosofía,México,4르 Ed. México Siglo XXI, 2007

CORTÉS IBARRA, Miguel Ángel, Derecho penal,México,1987,3aㅡ Ed. Cárdenas Editor.

DE PINA, RAFAEL Y DE PINA VARA, Rafael. Diccionario de derecho, México, Ed. Porrúa, 1997,

GUASTINI, Riccardo, Estudios sobre la interpretación jurídica. México Ed. Porrúa -UNAM, 2001

HALLIVIS PELAYO, Manuel, Teoría general de la interpretación. México,Ed.Porrúa, 2007.

KELSEN, Hans, Teoría pura del derecho, México, Ed. Porrúa, 1997

LARENZ, Karl, Metodología de la ciencia del derecho, Barcelona España,Ed. Ariel, 1994.

LARIOS, Rogelio y CABALLERO, Lucila, Las directivas de Interpretación jurídica. Hermosillo,Sonora,México Ed. Unison-Fontamara, 2011

MARGAÍN, MANATOU, Emilio, Introducción al estudio del derecho tributario mexicano. México,17를. Porrúa, 2012

MARMOR, Andrei, Interpretación y teoría del derecho, Barcelona, España, Ed.Gedisa, 2001

OVALLE FAVELA, José, Garantías constitucionales del proceso, México, Ed. McGraw-Hill, 1997

PÉREZ CARRILLO, Agustín, La derrotabilidad del derecho, Biblioteca de Filosofía del Derecho y Política. No. 89, México, Ed. Fontamara,2003

MENDONCA, Daniel, Las claves del derecho, Barcelona,España,Ed. Gedisa, 2008

ROSS ALF, Sobre el derecho y la justicia, 2ª Ed., Buenos Aires,Argentina, EUDEBA, 1997 


\section{La interpretación jurídica y la materia fiscal}

Año 11, Número 20, julio-diciembre de 2019

Rogelio Larios Velasco y Lucila Caballero Gutiérrez

SCHMILL, Ulises y COSSíO, José Ramón, "Interpretación del derecho y

concepciones del mundo", Interpretación jurídica y decisión judicial, Rodolfo

Vázquez compilador. Doctrina jurídica contemporánea. No. 4. $2^{\underline{a}}$ ed.

México,Ed. Fontamara, 2001

VERNENGO, Roberto, "Interpretación del derecho". El derecho y la justicia.

Enciclopedia Iberoamericana de Filosofía. No. 11. Madrid,Ed.Trotta, 1996

WRÓBLEWSKI, Jerzy, Constitución y teoría general de la interpretación jurídica,

Madrid, Ed.Cívitas, 1988

WRÓBLEWSKI, Jerzy, Sentido y hecho en el derecho, Doctrina jurídica

contemporánea. No. 9. México, Ed. Fontamara, 2001

Recibido 20 de Octubre de 2019

Aceptado 2 de Diciembre de 2019 